\title{
Factors associated with transitions between frailty states among older persons in Brazil, 2006-2010
}

\section{Fatores associados às transições nos estados de fragilidade entre idosos no Brasil, 2006-2010}

\author{
Luciana Correia Alves $^{1}$ (D), Jair Licio Ferreira Santos ${ }^{2}$ (D), Yeda Aparecida de Oliveira Duarte ${ }^{3}$ (D) \\ 'Department of Demography, University of Campinas (Unicamp) - Campinas (SP), Brasil. \\ ${ }^{2}$ Faculty of Medicine of Ribeirão Preto, University of São Paulo (USP) - Ribeirão Preto (SP), Brasil. \\ ${ }^{3}$ Medical-Surgical Nursing Department, University of São Paulo (USP) - São Paulo (SP), Brasil.
}

How to cite: Alves LC, Santos JLF, Duarte YAO. Factors associated with transitions between frailty states among older persons in Brazil, 2006-2010. Cad Saúde Colet, 2021;29(esp.):73-85. https://doi.org/10.1590/1414-462X202199010328

\begin{abstract}
Background: Frailty is considered one of the major conditions faced by ageing societies. Little has been reported about the transitions between the different frailty states in developing countries. Objective: This study aimed to identify the factors associated with transitions between frailty states between 2006 and 2010 among older adults in Brazil. Method: The present investigation is part of the SABE study (Health, Well-being and Ageing). Frailty state was classified according to the Fried's criteria (nonfrail, prefrail, and frail). The final study sample was composed of 1,399 individuals representing 1,019,243 older adults in the city of Sao Paulo, Brazil. Multiple logistic regression was used to identify factors associated with changes in frailty states. Results: Women were more likely to present a decline in frailty states. In the prefrail-to-nonfrail model, level of education was the most strongly associated factor. Advanced age and difficulty in performing at least one basic activity of daily living reduced in 9 and $64 \%$ the risk of becoming nonfrail, respectively. Conclusion: Addressing the factors associated with transition between frailty states among older adults is essential. Adequate interventions are important to reduce vulnerability and improve the health and well-being of older persons.
\end{abstract}

Keywords: ageing; frailty; transitions; risk factors; Brazil.

\begin{abstract}
Resumo
Introdução: A fragilidade é considerada uma das principais condições enfrentadas pelas sociedades que envelhecem. Poucos estudos têm explorado as transições entre os diferentes estados de fragilidade nos países em desenvolvimento. Objetivo: Identificar os fatores associados às transições de estado de fragilidade dos idosos no Brasil no período entre 2006 e 2010. Método: A presente investigação é parte do estudo SABE (Saúde, Bem-Estar e Envelhecimento). O estado de fragilidade foi classificado de acordo com os critérios da Fried (não frágil, pré-frágil e frágil). A amostra final era composta por 1.399 indivíduos que representam 1.019.243 idosos na cidade de São Paulo. Modelos de regressão logística binária múltiplo foram estimados para identificar os fatores associados às mudanças no estado de fragilidade. Resultados: As mulheres eram mais propensas a declinar para o estado de fragilidade. No modelo de pré-frágil para não frágil, o nível de escolaridade foi o fator mais fortemente relacionado. Aumento na idade e dificuldade em pelo menos uma atividade básica de vida diária reduziram em $9 \%$ e $64 \%$ o risco de se tornar não frágil, respectivamente. Conclusão: Abordar os fatores associados com as transições de estados de fragilidade entre idosos é essencial. Adequadas intervenções são importantes para reduzir vulnerabilidade e melhorar a saúde e bem-estar dos idosos.
\end{abstract}

Palavras-chave: envelhecimento; fragilidade; transições; fatores de risco; Brasil.

This is an Open Access article distributed under the terms of the Creative Commons Attribution License, which permits unrestricted use, distribution, and reproduction in any medium, provided the original work is properly cited.
Study carried out at city of Sao Paulo (SP), Brazil.

Correspondence: Luciana Correia Alves. E-mail: Icalves@unicamp.br

Financial support:This study was supported by the Sao Paulo Research Foundation (FAPESP), grant nos. 1999/05125 (wave 1), 2005/54947-2 (wave 2), and 2009/53778-3 (wave 3). FAPESP also provided funding for LCA (2011/05780-9; post-doctorate). Received on: Sep. 23, 2019. Accepted on: Dec. 26, 2019 


\section{INTRODUCTION}

Brazil has experienced a rapid process of demographic transition in the past five decades. Mortality has declined significantly since 1940. This reduction in mortality levels was much more rapid than that experienced by developed countries. Life expectancy at birth has increased by 30 years between the 1940s and the 2000s'. The Brazilian Demographic Census of 2010 showed that life expectancy reached 73.8 years ${ }^{2}$.

With population aging, there is growing concern regarding health and quality of life among older adults. The quest for longevity, adequate health, and well-being is one of the primary values cultivated throughout the history of humanity, and is part of the desires of the older population in Brazil, whose main concerns are health and health care ${ }^{3}$. The process of demographic and epidemiological transition has led to important changes in the health of the population, with greater prevalence of chronic-degenerative diseases, functional disability, and frailty.

Frailty is considered one of the major conditions faced by ageing societies ${ }^{4}$, and is an indicator of falls, hospitalization, prolonged the hospital stay, development of non-transmissible chronic diseases, disability, and death among older persons ${ }^{5}$. This makes frailty an important public health problem. Frailty is defined as a geriatric syndrome that results from a multisystemic decline in physiologic reserve and capacity, leading to high risk for several adverse conditions ${ }^{6}$. The main mechanisms of frailty are changes related to the aging process and the occurrence of comorbidities?.

The incomplete understanding of the epidemiology of frailty has been an obstacle to the development of specific intervention strategies. Few studies have addressed this issue because of the lack of a valid, standardized, operational definition of the concept ${ }^{8}$. According to Fried et al. ${ }^{7}$, frailty is determined by unintentional weight loss, self-reported exhaustion or fatigue, low level of physical activity, muscle weakness, and reduced gait speed. Individuals with none of these characteristics are considered nonfrail, prefrail individuals present one or two of these characteristics, and those with more than three characteristics are classified as frail.

Data from the Longitudinal Aging Study Amsterdam revealed a $19 \%$ frailty prevalence rate among 1,720 community-dwelling individuals aged $\geq 65$ years $^{5}$. Using different criteria, the Cardiovascular Health Study found a $6.9 \%$ frailty prevalence rate among older adults ${ }^{7}$. In Brazil, Duarte et al. ${ }^{9}$ studied a subsample of the SABE (Health, Well-being and Ageing) study involving individuals aged $\geq 75$ years in the city of São Paulo in 2006 and found a $15.4 \%$ frailty prevalence rate ${ }^{10}$.

This three-level definition of frailty proposed for Fried et al.7 has strong concurrent validity, as evidenced by expected associations with a series of physiological, sociodemographic, psychological and nutritional factors ${ }^{11}$. However, little is known about the transitions between frailty states (nonfrail, prefrail, and frail) over time and its associated factors. Studies investigating the transitions between frailty states have been conducted in North America ${ }^{8,12}$ and China ${ }^{13}$; however, there are no studies with populations in the other countries, including Brazil.

Understanding the history of transitions between frailty states will enable better future health care planning. Moreover, the detection of unfavorable factors allows the anticipation of problems and provides valuable information for the establishment of health policies and actions, thereby favoring the development of effective health promotion, care and prevention programs.

The present study aimed to identify factors associated with transitions between frailty states in a cohort of community-living Brazilian older persons from 2006 to 2010.

\section{METHOD}

The present investigation was developed based on data from the SABE study coordinated by the Pan American Health Organization (PAHO) started in 2000. The original SABE study was a household population-based, cross-sectional survey that aimed to investigate different aspects related to the health of older populations living in urban areas in seven Latin American and Caribbean countries: Argentina, Barbados, Brazil, Chile, Cuba, Mexico, and Uruguay. In Brazil, the 
SABE study was limited to the city of São Paulo. A total of 2,143 community-dwelling individuals aged $\geq 60$ years were interviewed between January 2000 and March $2001^{10}$.

A two-stage sampling process was conducted. Census sectors of the city were randomly selected in the first stage, and residences from each census sector were randomly selected in the second stage. In each household, all individuals aged $\geq 60$ years were interviewed regardless of their marital status or degree of kinship. Further details on the sampling design are available in Lebrão and Duarte ${ }^{10}$.

In 2006, the SABE study in Brazil became a longitudinal survey. The cohort from 2000 was located, and 1,115 individuals were interviewed a second time. Losses in the period corresponded to deaths $(22.9 \%)$, refusals to participate $(9.6 \%)$, changes of address to another city (2.5\%), cases of institutionalization (0.4\%), and individuals not located (12.6\%). This cohort was denominated $\mathrm{A}_{06}$. Further probabilistic, randomized sampling was performed to include a cohort of 298 additional individuals aged 60-64 years (cohort $B_{06}$ ). Another survey of the SABE study was conducted in 2010. Cohorts $A_{06}$ and $B_{06}$ were located and interviewed again $(n=990)$. Losses in the period were due to deaths (11.9\%), refusals to participate, changes of address to another city, cases of institutionalization, and individuals not located (18.0\%). In 2011, a probabilistic, randomized sampling was performed to include a cohort of 355 additional individuals aged 60-64 years (cohort $\mathrm{C}_{10}$ ). Figure 1 illustrates the evolution of these cohorts over time.

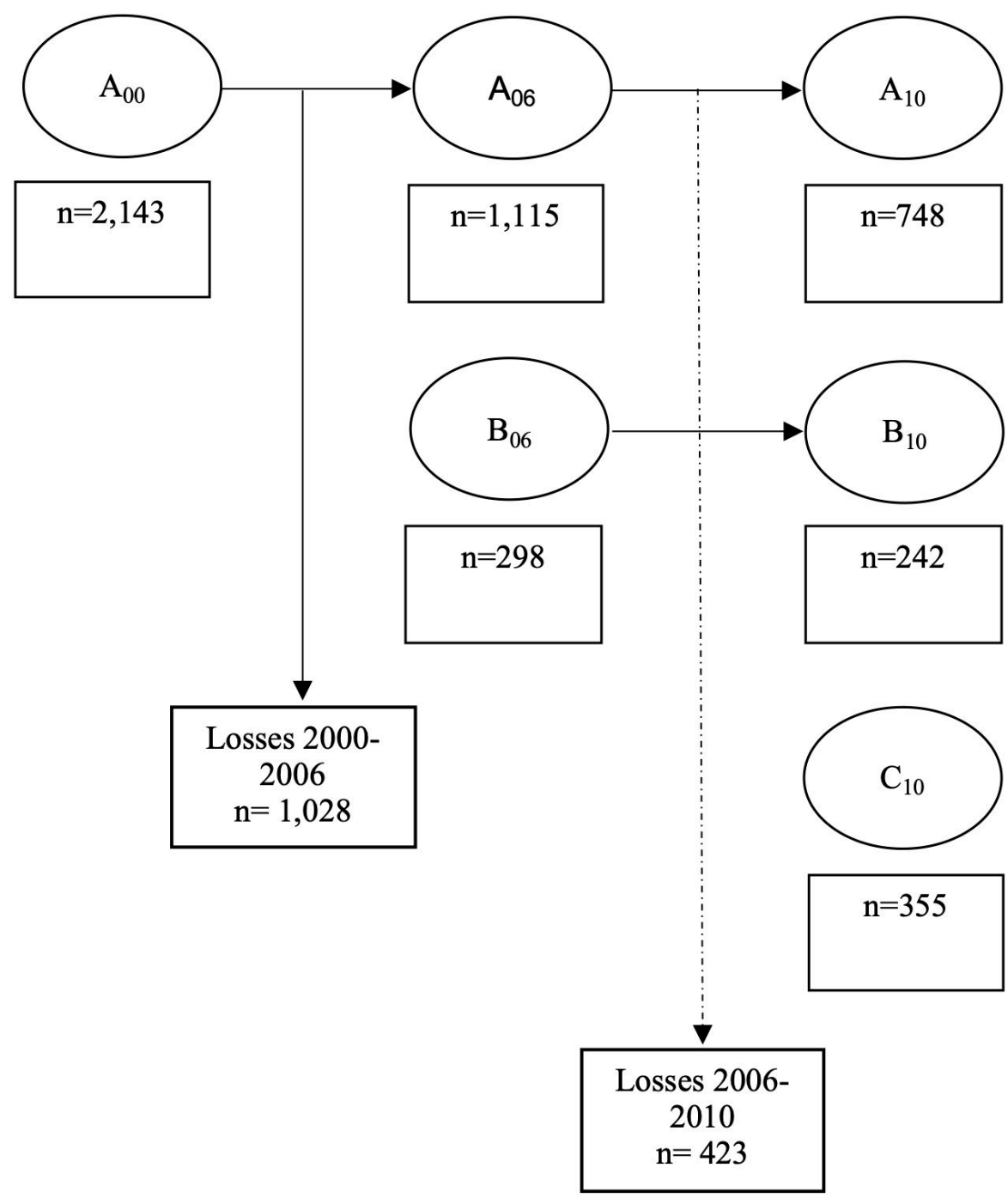

Figure 1. Flowchart of the SABE study cohorts 
This analysis uses the 2006 survey as baseline because data on frailty were not collected in 2000 . Among the 1,413 participants interviewed in 2006 , only 1,399 (99.0\%) older adults from cohorts $A_{06}$ and $B_{06}$ were included in the final sample. A total of 14 individuals who did not have correct information about frailty were excluded. Thus, the present observational cohort study involved older persons followed up from 2006 to 2010, representing 1,019,243 older adults in the city of São Paulo.

Frailty was defined according to Fried et al. ${ }^{7}$, who stated that it is a clinical syndrome in which three or more of the following criteria are present: unintentional weight loss, diminished muscle strength, complaints of fatigue or exhaustion, reduced gait speed, and low level of physical activity.

Loss of muscle strength was evaluated based on grip strength measured using a manual dynamometer (Takei Kiki Kogyio TK 1201, Japan). Grip strength was determined for the dominant hand, with the participant seated, elbow on a table, and both forearm and palm turned upward. Each participant was instructed to perform maximum possible force. Two trials were performed, with a one-minute rest between them. The readings were made in kilograms $(\mathrm{Kg})$ and the cutoff points were stratified by sex and body mass index (BMI) based on the criteria established by Fried et al.?

Body mass was determined using a portable scale (SECA manufactured) with capacity for $150 \mathrm{Kg}$ and sensitivity of $1 / 2 \mathrm{Kg}$. The individuals were barefoot and wearing the least possible clothes. Height was measured based on the Frisancho anthropometric standard using a Harpender 3 stadiometer. BMI was calculated based on body mass and height (Kg/ $\mathrm{m}^{2}$ ). A nominal qualitative variable was created for the presence and/or absence of reduced strength based on the smallest quintile of this variable stratified by sex and BMI.

Fatigue or exhaustion was determined based on the answers to the following questions: "How often in the last week did you feel like everything you did was an effort?" and "How often in the last week could you not get going?" A dichotomized nominal variable was then created: yes (a moderate amount of time + most of the time) or no (rarely or none of the time + some or a little of the time).

The walk test, which is part of the Short Physical Performance Battery Assessing Lower Extremity Function, was used to determine gait speed ${ }^{14}$. The participant was asked to walk 3.05 meters without obstacles at their habitual walking pace and was allowed to use a gaitassistance device if needed. Each participant performed the walk test twice, and the shorter time was considered for the analysis. The results were distributed into quintiles stratified by height and sex. A qualitative nominal variable was then created for the presence/absence of a decline in gait speed based on height for sex.

A version in Portuguese of the International Physical Activity Questionnaire was used to evaluate the degree of physical activity ${ }^{15}$. To this end, the metabolic cost (measured in metabolic equivalent of task - MET) of each activity was used, along with the number of days per week the activity was practiced, and the time required to complete the task. MET values were transformed into Kcal and analyzed in quintiles stratified by sex.

A frailty index with a continuous scale ( 0 to 5 ) was constructed based on the presence/ absence of each of the five frailty components. Individuals with none of these characteristics were classified as nonfrail, those with one or two were classified as prefrail, and those with three or more were classified as frail.

The dependent variable was the change in frailty state between 2006 (baseline) and the follow-up period identified in the data of 2010 (between the 2006 and 2010 interviews). The independent variables were categorized as follows: demographic (age, sex, marital status, living arrangement); socioeconomic (schooling, employment status, household income); healthrelated (self-rated health, self-reported chronic diseases, depression, cognitive decline, number of chronic diseases, falls and hospitalizations in the previous 12 months, body mass index [BMI], functional capacity, use of medications); lifestyle-related (practice of regular physical activity, alcohol intake, smoking, consumption of fruits and vegetables); socially related (going to movies/restaurants, visiting friends and family members, participating in organized social activities, receiving guests). 
Chronic diseases were recorded based on the answer to the following question: "Has a doctor or nurse ever told you that you have....?" Nine chronic diseases were investigated: hypertension, diabetes, lung disease, heart disease, embolism/stroke, arthritis/arthrosis/ rheumatism, cancer, osteoporosis, and psychiatric disorders.

Functional capacity was measured based on basic activities of daily living (BADL) (walking across a room, feeding oneself, lying down and getting up from a bed, toileting, dressing/ undressing, and taking a bath/shower), instrumental activities of daily living (IADL) (managing money, transportation, shopping, using a telephone, and taking medications), and mobility (difficulty walking one block, remaining seated for hours, standing up from a chair, going up a flight of stairs, bending over, kneeling or squatting, extending the arms above the shoulders, and lifting or carrying more than five $\mathrm{Kg}$ of weight). Participants who reported difficulty or inability to perform at least one of the tasks on each dimension were recorded as "having difficulty".

Descriptive statistics were calculated for all variables. A multiple logistic regression model was used to identify significant factors associated with changes between frailty states (nonfrail, prefrail, and frail). Initially, a simple binary logistic regression model was carried out with each variable. The statistically significant variables $(p<0.20)$ in the univariate regression analysis were selected for multiple binary logistic regression analysis. In the multivariate analysis, a decision was made to include all independent variables simultaneously in a single model. Age and gender could confound the outcome; however, these variables were included in all multiple logistic models. Risk ratios (RR) and $95 \%$ confidence intervals $(95 \% \mathrm{Cl})$ were calculated to evaluate the factors associated with frailty state. As proposed by Lee et al. ${ }^{13}$, regressions were performed separately for frailty groups as categorized at baseline (nonfrail, prefrail, and frail). Directions of change examined included (1) prefrail to frail, (2) prefrail to nonfrail, (3) nonfrail to prefrail or frail, and (4) frail to prefrail or nonfrail.

To ensure the representativeness of the total population, weights were incorporated into the data to expand the sample. To prevent cluster effects from causing a significant impact on the precision of the estimates, which could lead to erroneous conclusions in the analysis of the hypothesis tests, aspects that defined the complex sampling procedure of the SABE study were incorporated into the estimation of these measures.

All statistical analyses were performed using the $R 3.4 .1$ software.

The present study was approved by the Human Research Ethics Committee of the School of Public Health, University of Sao Paulo (USP) and the National Research Ethics Committee. Participation was voluntary, and all participants signed an Informed Consent Form (ICF) prior to study commencement.

\section{RESULTS}

The results showed that 8.5 and $41.5 \%$ of the interviewees were frail and prefrail, respectively, in 2006. At the follow-up, of those classified as nonfrail at baseline, $48.3 \%$ had remained in the same state ( $35.9 \%$ men), $27.7 \%$ worsened to prefrail ( $60.3 \%$ women), and $1.8 \%$ to frail (62.4\% women). Regarding the prefrail individuals in $2006,7.8 \%$ had progressed to the frailty state (60.7\% women), $23.6 \%$ had recovered to the nonfrail state (60.6\% women), and $36.6 \%$ remained prefrail in 2010 ( $37.2 \%$ men). Among those classified as frail at baseline, 4.0 and $27.5 \%$ recovered to the nonfrail and prefrail, respectively (39.4 and 37.2 men, respectively). Approximately $17.2 \%$ remained in the frail state ( $60.7 \%$ women).

Considering the older adults classified as nonfrail at baseline, the incidence rate at the follow-up for the prefrail and frail states was $43.4 / 1,000$ and $2.9 / 1,000$, respectively. In the prefrail group, the incidence rate was $30.8 / 1.000$ for nonfrail and $10.1 / 1000$ for frail. In the frail category, the incidence rate was $1.1 / 1,000$ for the nonfrail and $7.3 / 1,000$ for the prefrail state in 2010 . For all states, there was an increase in the incidence rate for recovery of the immediately previous category.

At baseline (2006), age ranged from 60 to 104 years (mean: $70 \pm 7.5$ years; median: 69 years). Tables 1 and 2 display some characteristics of the sample. The population was predominantly female (59.4\%); $86.6 \%$ lived with others; $57.2 \%$ were either married or in a stable relationship; $53.8 \%$ had between one and four years of schooling; $63.4 \%$ were unemployed; $38.6 \%$ received between one and three times the Brazilian monthly minimum wage (Table 1). 
Table 1. Relative distribution (\%) of demographic and socioeconomic characteristics of older adults in the city of Sao Paulo, Brazil, 2006 (baseline)

\begin{tabular}{|c|c|c|}
\hline Variables & n $(1,019,243)$ & Relative distribution (\%) \\
\hline \multicolumn{3}{|l|}{ Age (years) } \\
\hline $60-64$ & 291575 & 28.6 \\
\hline $65-69$ & 276147 & 27.1 \\
\hline $70-74$ & 202625 & 19.9 \\
\hline $75-79$ & 128466 & 12.6 \\
\hline$\geq 80$ & 120430 & 11.8 \\
\hline \multicolumn{3}{|l|}{ Sex } \\
\hline Male & 413971 & 40.6 \\
\hline Female & 605272 & 59.4 \\
\hline \multicolumn{3}{|l|}{ Marital status } \\
\hline Single & 43679 & 4.3 \\
\hline Married/Stable union & 583447 & 57.2 \\
\hline Separated/Divorced & 78348 & 7.7 \\
\hline Widowed & 312778 & 30.7 \\
\hline \multicolumn{3}{|l|}{ Living arrangement } \\
\hline Lives alone & 134620 & 13.2 \\
\hline Lives with others & 882933 & 86.6 \\
\hline \multicolumn{3}{|l|}{ Schooling (years) } \\
\hline None & 199396 & 19.6 \\
\hline 1 to 4 & 548739 & 53.8 \\
\hline$\geq 5$ & 270385 & 26.5 \\
\hline \multicolumn{3}{|l|}{ Employment status } \\
\hline Employed & 287474 & 28.2 \\
\hline Unemployed & 646585 & 63.4 \\
\hline \multicolumn{3}{|l|}{ Income } \\
\hline None & 33329 & 3.3 \\
\hline Less than BMMW & 186715 & 18.3 \\
\hline 1 to 2.99 times BMMW & 393936 & 38.6 \\
\hline 3 to 4.99 times BMMW & 146152 & 14.3 \\
\hline 5 or more times BMMW & 141781 & 13.9 \\
\hline
\end{tabular}

Source: SABE study, $2006^{10}$. BMMW = Brazilian monthly minimum wage. Numbers and percentages that are missing refer to the category without information

Approximately $44.6 \%$ of the interviewees rated their health as good. The most frequent chronic disease was arterial hypertension (62.5\%), followed by arthritis/arthrosis/rheumatism $(32.3 \%)$, heart disease $(22.0 \%)$, diabetes $(20.9 \%)$, osteoporosis $(21.7 \%)$, and depression (13.1\%). Approximately $42.6 \%$ of them reported two to three chronic diseases, $13.7 \%$ reported psychiatric problems, $9.6 \%$ reported hospitalization in the previous 12 months, $28.5 \%$ reported falls in the previous 12 months, $90.6 \%$ took medications, $21.9 \%$ were classified as obese, and $28.1 \%$ presented cognitive decline. Regarding functional status, $41.2 \%$ had difficulty with at least one IADL, $88.7 \%$ had some difficulty mobility, and $22.7 \%$ had difficulty with at least one BADL. Concerning lifestyle, $80.4 \%$ consumed fruits and vegetables, $30.9 \%$ consumed alcohol, $14.1 \%$ were smokers, and $17.4 \%$ practiced physical activity regularly (Table 2 ). Additionally, at baseline, most of interviewees received guests and/or visited friends and family members ( 59.9 and $65.4 \%$, respectively). Approximately $38.6 \%$ the older individuals went to the movies/ restaurants and $38.1 \%$ participated in organized social activities. 
Table 2. Relative distribution (\%) of health, functional status, and lifestyle characteristics among older adults in the city of Sao Paulo, Brazil, 2006 (baseline)

\begin{tabular}{|c|c|c|}
\hline Variable & $\begin{array}{c}n \\
(1,019,243) \\
\end{array}$ & Relative distribution (\%) \\
\hline \multicolumn{3}{|l|}{ Self-rated health } \\
\hline Good & 454503 & 44.6 \\
\hline Fair & 468385 & 46 \\
\hline Poor & 89461 & 8.8 \\
\hline \multicolumn{3}{|l|}{ Hypertension* } \\
\hline Yes & 636783 & 62.5 \\
\hline \multicolumn{3}{|l|}{ Diabetes* } \\
\hline Yes & 213333 & 20.9 \\
\hline \multicolumn{3}{|l|}{ Lung disease * } \\
\hline Yes & 121576 & 11.9 \\
\hline \multicolumn{3}{|l|}{ Heart disease* } \\
\hline Yes & 224073 & 22 \\
\hline \multicolumn{3}{|l|}{ Embolism/stroke* } \\
\hline Yes & 84070 & 8.2 \\
\hline \multicolumn{3}{|l|}{ Arthritis/arthrosis/rheumatism* } \\
\hline Yes & 329656 & 32.3 \\
\hline \multicolumn{3}{|l|}{ Cancer* } \\
\hline Yes & 48344 & 4.7 \\
\hline \multicolumn{3}{|l|}{ Osteoporosis* } \\
\hline Yes & 221487 & 21.7 \\
\hline \multicolumn{3}{|l|}{ Psychiatric disorders* } \\
\hline Yes & 139199 & 13.7 \\
\hline \multicolumn{3}{|l|}{ Depression** } \\
\hline Yes & 133275 & 13.1 \\
\hline \multicolumn{3}{|l|}{ Cognitive decline ${ }^{* * *}$} \\
\hline Yes & 286081 & 28.1 \\
\hline \multicolumn{3}{|l|}{ Number of chronic diseases } \\
\hline 0 & 141195 & 13.9 \\
\hline 1 & 252087 & 24.7 \\
\hline $2-3$ & 434419 & 42.6 \\
\hline$\geq 4$ & 191542 & 18.8 \\
\hline \multicolumn{3}{|l|}{ Fall in the previous 12 months } \\
\hline Yes & 290220 & 28.5 \\
\hline \multicolumn{3}{|c|}{ Hospitalization in the previous 12 months } \\
\hline Yes & 98259 & 9.6 \\
\hline \multicolumn{3}{|l|}{ Use of medications } \\
\hline Yes & 923046 & 90.6 \\
\hline \multicolumn{3}{|l|}{ Body mass index } \\
\hline Underweight & 211774 & 20.8 \\
\hline Ideal range & 426549 & 41.8 \\
\hline Overweight & 116384 & 11.4 \\
\hline Obesity & 223191 & 21.9 \\
\hline \multicolumn{3}{|l|}{ Difficulty with at least one IADL } \\
\hline Yes & 419951 & 41.2 \\
\hline Difficulty with at least one mol & & \\
\hline Yes & 904303 & 88.7 \\
\hline Difficulty with at least one $B A D$ & & \\
\hline Yes & 231215 & 22.7 \\
\hline Regular physical activity & & \\
\hline Yes & 177309 & 17.4 \\
\hline Alcohol consumption & & \\
\hline Yes & 315338 & 30.9 \\
\hline Smoking & & \\
\hline Non-smoker & 528118 & 51.8 \\
\hline Smoker & 143420 & 14.1 \\
\hline Ex-smoker & 347705 & 34.1 \\
\hline Consumption of fruits and veg & & \\
\hline Yes & 819876 & 80.4 \\
\hline
\end{tabular}

Source: SABE study, $2006^{10}$.

*Self-reported; **Measured by the Geriatric Depression Scale; ***Mini Mental Health Examination.

IADL: instrumental activity of daily living; BADL: basic activity of daily living. Numbers and percentages that are missing refer to the category without information 
In the univariate analysis, the variables associated with risk of occurrence of a frailty state $(p<0.20)$ in the four models (prefrail to frail, prefrail to nonfrail, nonfrail to prefrail or frail, and frail to prefrail or nonfrail) were incorporated into the multivariate analysis. Table 3 shows the risk ratio (RR) to factors significantly associated with transitions between frailty states. In the prefrail-to-frail model, the results revealed that the risk of frailty among prefrail individuals increased with age $(R R=1.13)$, those with diabetes $(R R=5.47)$, cancer $(R R=8.50)$, osteoporosis $(R R=5.26)$ and obesity $(R R=3.67)$. The risk of frailty was lower among females $(R R=0.29)$, those with four or more chronic diseases ( $R R=0.02$ ), and ideal range and excess weight ( $R R=0.84$ and $R R=0.04$, respectively) compared with males who presented absence of chronic diseases and underweight.

Table 3. Risk ratio to factors significantly associated with transitions between frailty states over four years in multiple logistic regressions of older adults in the city of Sao Paulo, Brazil, 2006 and 2010

\begin{tabular}{|c|c|c|c|c|}
\hline \multirow{2}{*}{ Variable } & Prefrail to Frail & $\begin{array}{c}\text { Prefrail to } \\
\text { Nonfrail }\end{array}$ & $\begin{array}{c}\text { Nonfrail to } \\
\text { Prefrail or Frail }\end{array}$ & $\begin{array}{c}\text { Frail to Prefrail or } \\
\text { Nonfrail }\end{array}$ \\
\hline & $\begin{array}{c}\text { Risk Ratio } \\
95 \% \mathrm{Cl}\end{array}$ & $\begin{array}{c}\text { Risk Ratio } \\
95 \% \mathrm{Cl}\end{array}$ & $\begin{array}{c}\text { Risk Ratio } \\
95 \% \mathrm{Cl}\end{array}$ & $\begin{array}{c}\text { Risk Ratio } \\
95 \% \mathrm{Cl}\end{array}$ \\
\hline Age (years) & $1.13(1.06-1.20)$ & $0.91(0.88-0.95)$ & $1.06(1.02-1.11)$ & - \\
\hline \multicolumn{5}{|l|}{ Sex } \\
\hline Male & 1 & - & - & 1 \\
\hline Female & $0.29(0.11-0.80)$ & & & $2.25(2.05-44.10)$ \\
\hline \multicolumn{5}{|l|}{ Schooling (years) } \\
\hline None & - & 1 & - & - \\
\hline 1 to 4 & & $2.48(1.12-5.50)$ & & \\
\hline$\geq 5$ & & $2.43(0.96-6.14)$ & & \\
\hline \multicolumn{5}{|l|}{ Diabetes } \\
\hline No & 1 & - & - & - \\
\hline Yes & $5.47(1.77-19.10)$ & & & \\
\hline \multicolumn{5}{|l|}{ Cancer } \\
\hline No & 1 & - & - & - \\
\hline Yes & $8.50(1.77-39.25)$ & & & \\
\hline \multicolumn{5}{|l|}{ Osteoporosis } \\
\hline No & 1 & - & - & - \\
\hline Yes & $5.26(1.49-19.88)$ & & & \\
\hline \multicolumn{5}{|c|}{ Number of chronic diseases } \\
\hline 0 & 1 & - & - & - \\
\hline 1 & $0.09(0.01-0.58)$ & & & \\
\hline $2-3$ & $0.06(0.01-0.51)$ & & & \\
\hline$\geq 4$ & $0.02(0.00-0.36)$ & & & \\
\hline \multicolumn{5}{|l|}{ Body mass index } \\
\hline Underweight & 1 & - & - & - \\
\hline Ideal range & $0.84(0.28-2.58)$ & & & \\
\hline Overweight & $0.04(0.00-0.56)$ & & & \\
\hline Obesity & $3.67(1.05-14.15)$ & & & \\
\hline \multicolumn{5}{|c|}{ Difficulty with at least one BADL } \\
\hline No & - & 1 & - & - \\
\hline Yes & & $0.36(0.16-0.80)$ & & \\
\hline \multicolumn{5}{|l|}{ Cognitive decline } \\
\hline No & - & - & - & 1 \\
\hline Yes & & & & $0.03(0.00-0.36)$ \\
\hline \multicolumn{5}{|c|}{ Regular physical activity } \\
\hline No & - & - & 1 & - \\
\hline Yes & & & $0.40(0.23-0.69)$ & \\
\hline \multicolumn{5}{|c|}{ Goes to the movies or restaurants } \\
\hline No & - & - & 1 & - \\
\hline Yes & & & $1.86(1.17-2.94)$ & \\
\hline Intercept & $p<0.01$ & $p<0.01$ & $p<0.01$ & $p>0.05$ \\
\hline
\end{tabular}


In the prefrail-to-nonfrail model, level of education was the strongest factor. Older persons with one or more years of schooling were most likely to be nonfrail than those without schooling. Age and difficulty in performing at least one BADL proved to be protective factors. Individuals with advanced age and difficulty in performing at least one BADL had 9 and $64 \%$ reduced risk of becoming nonfrail, respectively.

In the nonfrail to prefrail or frail model, older adults who went to the movies or restaurants presented the highest risk ( $R R=1.86)$. Advanced age had $6 \%$ greater risk of becoming prefrail or frail. Older persons who practiced physical activities regularly had $60 \%$ lower risk compared with those with no activity ( $R R=0.40)$.

Frail female individuals presented a 1.25 -fold greater risk of becoming prefrail or nonfrail compared with frail males. Older individuals with cognitive decline presented reduced the risk of being classified as prefrail or nonfrail compared with those without cognitive decline; however, this model was not statistically significant (intercept: $p>0.05$ ).

Results of the residual analysis showed that model presented high goodness of fit.

\section{DISCUSSION}

With the greater longevity and ageing of the population, frailty has become an important public health problem among older persons, placing new demands on the services available in the healthcare system. In fact, frailty is another impairment to the health condition. However, little is known about the transitions between frailty states over time. This is the first study to report transitions between frailty states among Brazilian older persons.

In the present study, the prevalence and incidence rates indicate that frailty is an insidious, progressive phenomenon that develops slowly over time among older persons in the city of Sao Paulo, Brazil. Approximately $7.8 \%$ of the older persons classified in the prefrail state in 2006 (baseline) had progressed to the frail state in 2010. Gill et al. ${ }^{8}$ conducted a retrospective study involving community-dwelling older persons in the United States to determine the rates of transition between frailty states and evaluate the effect of previous frailty states on the subsequent transition to frailty, and found that nearly $43.3 \%$ of the individuals analyzed progressed to the frail state within a period of only 18 months. In other words, the transition between frailty states observed by those authors occurred much faster than in this study. A possible explanation for the results found in the city of Sao Paulo lies on the fact that frailty occurs in more advanced stages of chronic diseases, particularly among older persons at more advanced ages. In fact, the sample of this study was composed particularly of a large number of individuals aged $<80$ years.

Age has proved to be an important risk factor for both the prefrail and frail states. The present findings agree with data reported in previous studies that show an association between advanced age and the development of frailty ${ }^{16}$ and lower risk of state improvement. The physiological process of aging causes changes in different systems of the body, resulting in loss of capacity. Thus, individuals become increasingly vulnerable with age. The musculoskeletal system undergoes important morphological changes throughout the aging process, with progressive reduction in lean body mass and muscle strength. This phenomenon is called sarcopenia ${ }^{17}$, and is considered a strong indicator of frailty.

The results of this study showed that men and women presented different transition rates. However, these findings contrast to those reported by Lee et al. ${ }^{13}$, who observed that more men than women progressed into frailty. In the present cohort, $60.7 \%$ of the prefrail women progressed into frailty in 2010. Men and women may experience different trends of epidemiologic transition. With increased longevity, women usually tend to present higher overall prevalence or incidence of diseases and disability and/or other complications compared with men $^{18}$. There is also the gender health paradox ${ }^{19}$. Women enjoy greater longevity but worse health, and this can be due to genetic risks, immune-system responses, hormones, disease patterns and prevention, health-reporting behaviors, and socioeconomic status ${ }^{20}$.

In the multivariate analysis, the present findings reveal that few demographic and socioeconomic factors were associated with frailty transitions in Brazil. Health and lifestyle 
were the most strongly related factors. Education level influenced only one of the transitions. Sex affected more importantly the transitions of the frailty advanced states, such as prefrail to frail and frail to prefrail or nonfrail. Adjusted for other factors, women were less likely to become frail compared with men. Moreover, women were most likely to recover from the most severe states, generally had greater insight into disease and their health conditions, and were more likely to seek self-care and medical assistance compared with men - all of which would tend to increase the likelihood of having health problems controlled, with greater possibility to reverse from more unfavorable states.

In the present study, education level was associated only with the transitions from the prefrail to nonfrail states for those who had between 1 and 4 years of schooling. Having 1 to 4 years of schooling increased the risk of individuals change from prefrail to nonfrail states compared with no schooling. As transition between frailty states occurs mainly towards the end of an individual's life, it is likely to occur at all socioeconomic levels. It is reasonable to assert that schooling does not directly impact on the pathophysiology of frailty, but it interferes in the individual's lifestyle, quality of life, and access to health care. Thus, no schooling can influence the frailty process ${ }^{21}$.

The results confirmed the findings by Lee et al. ${ }^{13}$, who reported the effect of comorbidities on changes in frailty states. Among the medical comorbidities studied, diabetes, cancer, and osteoporosis were the most consistent adverse factors, contributing to an increased risk of the transition from prefrail to frail states in 2010. These findings also corroborate those of Espinoza et al. ${ }^{12}$, who found that diabetes is a dangerous condition in the prefrail state. Diabetes predisposes older persons to more rapid muscle loss and functional decline, and metabolic risk factors are associated with poorer physical performance ${ }^{13,22,23}$. Having cancer increased the risk of worsening in the prefrail and robust states by eight times. Because both cancer itself, as well as the therapies offered to treat it, can be significant additional stressors that challenge a patient's physiologic reserve, the incidence of frailty in older cancer patients is especially high. Osteoporosis increases the risk of falls, fractures, and other fall-related injuries, causing frailty. However, the number of chronic diseases was not a harmful condition in the prefrail to frail state, but rather it was a protective factor. It is possible that frailty per se is not linked to the number of chronic diseases, but associated with a specific disease. In other words, it is not the number that determines the condition of frailty, but the type of disease, such as more severe chronic degenerative diseases.

Physical activity was a protective factor in the nonfrail state, reducing the development of transitions from the prefrail or frail states in 2010. Interventions that help to maintain or improve the level of physical activity might play a role in reducing decline or improving recovery in these groups. Facilitating a better physical performance among older persons leads to improvements in muscle strength, flexibility, aerobic capacity, and balance, with subsequent reduction in the number of falls, disability, and development of frailty syndrome.

This study found that cognitive decline reduced by $97 \%$ the risk of transitions from the frail to prefrail or nonfrail states. In fact, declined cognitive reserve leads to mild cognitive impairment and dementia, which run parallel to the course of physical frailty. Although the Fried's phenotype does not include cognition as one of its criteria, it shows that cognition is highly associated with frailty syndrome ${ }^{7}$.

Obesity was a harmful condition in the transition from the prefrail to frail states. Sarcopenic obesity is common among frail older persons, and is characterized by increased body mass due to fat deposits, together with reduction in lean mass in the extremities, making these individuals frail ${ }^{24-27}$. On the other hand, excess weight proved to be a protective factor against frailty among prefrail older persons in the city of Sao Paulo. Overweight older adults have more energy reserve and are at a reduced risk for osteoporosis and injurious falls, and thus present decreased risk of functional limitations, disability, and frailty. Thus, some excess body weight in later life may be beneficial to prefrail and frail older adults.

Difficulty with at least one BADL was detrimental to the prefrail to nonfrail states. In fact, difficulty with at least one BADL reduced the risk of frailty improvement. Disability and frailty have some characteristics in common: they are both rather prevalent in the older population, 
are of multifactorial nature, and share some risk factors and pathophysiological mechanisms ${ }^{28}$. Fried et al. ${ }^{7}$ claimed that frailty can also be a precursor of disability; however, one cannot overlook the possibility of reverse causality between functional status and frailty.

Older persons who go to the movies or restaurants presented a greater risk of transitioning from nonfrail to prefrail or frail states. Therefore, this finding is surprising. According to Rockwood et al. ${ }^{29}$, frailty occurs more commonly in older persons who are socially isolated. It is likely that older persons who do activities such as walking, shopping, or taking part in social activities may be more susceptible to accidents such as falls and, consequently, advance to prefrail and frail states.

Frailty is considered a consequence of chronic diseases, disability, hospitalizations, falls, immobility, among others ${ }^{5}$. In these cases, health factors are perhaps more relevant to determine the various frailty states than demographic and socioeconomic factors, whose greatest influence is on other health indicators, such as chronic diseases.

Lee et al. ${ }^{13}$ examined the natural history of transitions between frailty states in a cohort of community-living older Chinese older adults stratified by sex. The present study found similar results investigating a probabilistic sample of community-dwelling older persons. Thus, the findings of the present study are innovative, and make an important contribution to the study of frailty states among older persons in Brazil, focusing on the city of Sao Paulo as part of this totality. These findings allow a better understanding of the epidemiology of frailty in developing countries.

Due to the multidimensional nature of this condition, future studies that incorporate physiological, clinical and genetic factors may assist in gaining a better understanding of the causalities of these relationships. However, interventions and strategies that stimulate improved physical and biological capacity should continue to be priorities. Facilitating a better physical performance among older adults leads to improvements in muscle strength, flexibility, aerobic capacity, and functional status. It may slow bone loss from osteoporosis and make older adults stronger, with a subsequent reduction in the development of frailty syndrome.

These findings underscore the importance of cohort studies, which constitute an essential tool for the monitoring, evaluation, and discussion on health and health care for older adults. However, limitations to this study should be addressed. The participants may have been submitted to some type of intervention between interviews, which could have led to changes to other frailty states. Nevertheless, it was not possible to control such interventions due to the fact that this information was not collected in the questionnaire of the SABE study.

Detection of the frailty process and recognition of the frailty states are necessary to postpone or prevent their multiple severe consequences. Frailty can be differentiated from ageing but, unlike ageing, it can be prevented and possibly reversed. A more comprehensive understanding of the physiopathological mechanisms of the frailty process will be instrumental in changing the perception of this concept ${ }^{30}$.

Finally, specific strategies and actions directed to slowing, minimizing, or recovering from frailty are of utmost importance. Public health policies aimed at avoiding the development of frailty among older persons at risk should be encouraged. Likewise, policies that suggest adequate interventions are important to restoring physical and biological capacity, as well as reducing the degree of vulnerability among frail older persons. In the prefrail period, an appropriate approach could either reverse the condition or, at least, slow its progress. Therefore, addressing the factors associated with transition between frailty states among older persons is essential to improving the quality of the management of individuals who are frail or at risk of becoming frail.

\section{ACKNOWLEDGEMENTS}

The authors acknowledge Prof. Maria Lucia Lebrão (in memorian). 


\section{REFERENCES}

1. de Carvalho JA, Garcia RA. O envelhecimento da população brasileira: Um enfoque demográfico. Cad Saude Publica. 2003;19(3):109-18. http://dx.doi.org/10.1590/S0102-311X2003000300005. PMid:12806475.

2. Instituto Brasileiro de Geografia e Estatística. Tábuas de mortalidade [Internet]. Rio de Janeiro: IBGE; 2010 [cited 2019 Sep 23]. Available from: http://www.ibge.gov.br/home/estatistica/populacao/projecao_ da_populacao/2013/

3. Litvoc J, Brito FC. Capacidade funcional. In: Litvoc J, Brito FC, editores. Envelhecimento: prevenção e promoção da saúde. São Paulo: Editora Atheneu; 2004. p. 17-36.

4. Levers MJ, Estabrooks CA, Ross KJC. Factors contributing to frailty: literature review. J Adv Nurs. 2006;56(3):282-91. https://doi.org/10.1111/j.1365-2648.2006.04021.x.

5. Puts MT, Lips P, Deeg DJ. Sex differences in the risk of frailty for mortality independent of disability and chronic diseases. J Am Geriatr Soc. 2005;53(1):40-7. http://dx.doi.org/10.1111/j.1532-5415.2005.53008.x. PMid:15667374.

6. Fried LP, Ferrucci L, Darer J, Williamson JD, Anderson G. Untangling the concepts of disability, frailty, and comorbidity: implications for improved targeting and care. J Gerontol A Biol Sci Med Sci. 2004;59(3):25563. http://dx.doi.org/10.1093/gerona/59.3.M255. PMid:15031310.

7. Fried LP, Tangen CM, Walston JD, Newman AB, Hirsch C, Gottdiener J, et al. Frailty in older adults: evidence for a phenotype. J Gerontol A Biol Sci Med Sci. 2001;56A(3):M146-56. http://dx.doi.org/10.1093/ gerona/56.3.M146. PMid:11253156.

8. Gill TM, Gahbauer EA, Allore HG, Han L. Transitions between frailty states among community-living older persons. Arch Intern Med. 2006;166(4):418-23. http://dx.doi.org/10.1001/archinte.166.4.418. PMid:16505261.

9. Duarte YAO, Nunes DP, Corona LP, Lebrão ML. Como estão sendo cuidados os idosos frágeis de São Paulo? A visão mostrada pelo Estudo SABE (Saude, Bem-estar, Envelhecimento). In: Camarano AA. Cuidados de longa duração para a população idosa: um novo risco social a ser assumido? Rio de Janeiro: IPEA, 2010. p. 123-44.

10. Lebrão ML, Duarte YAO. SABE-Saúde, bem-estar e envelhecimento - O Projeto SABE no município de São Paulo: uma abordagem inicial. Brasília: Organização Pan-Americana da Saúde; 2003.

11. Mello AC, Engstrom EM, Alves LC. Health-related and socio-demographic factors associated with frailty in the elderly: a systematic literature review. Cad Saude Publica. 2014;30(6):1143-68. http://dx.doi. org/10.1590/0102-311X00148213. PMid:25099040.

12. Espinoza SE, Jung I, Hazuda H. Frailty transitions in the San Antonio Longitudinal Study of Aging. J Am Geriatr Soc. 2012;60(4):652-60. http://dx.doi.org/10.1111/j.1532-5415.2011.03882.x. PMid:22316162.

13. Lee JS, Auyeung TW, Leung J, Kwok T, Woo J. Transitions in frailty states among community-living older adults and their associated factors. J Am Med Dir Assoc. 2014;15(4):281-6. http://dx.doi.org/10.1016/j. jamda.2013.12.002. PMid:24534517.

14. Guralnik JM, Simonsick EM, Ferrucci L, Glynn RJ, Berkman LF, Blazer DG, et al. A short physical performance battery assessing lower extremity function: association with self-reported disability and prediction of mortality and nursing home admission. J Gerontol. 1994;49(2):M85-94. http://dx.doi.org/10.1093/ geronj/49.2.M85. PMid:8126356.

15. Guedes DP, Lopes CC, Guedes JERP. Reprodutibilidade e validade do Questionário Internacional de Atividade Física em adolescentes. Rev Bras Med Esporte. 2005;11(2):151-7. http://dx.doi.org/10.1590/ S1517-86922005000200011.

16. Vieira RA, Guerra RO, Giacomin KC, Vasconcelos KSS, Andrade ACS, Pereira LSM, et al. Prevalência de fragilidade e fatores associados em idosos comunitários de Belo Horizonte, Minas Gerais, Brasil: dados do estudo FIBRA. Cad Saude Publica. 2013;29(8):1631-43. http://dx.doi.org/10.1590/S0102311X2013001200015. PMid:24005928.

17. Mühlberg W, Sieber C. Sarcopenia and frailty in geriatric patients: implications for training and prevention. Z Gerontol Geriatr. 2004;37(1):2-8. http://dx.doi.org/10.1007/s00391-004-0203-8. PMid:14991289.

18. Gu D, Gomez-Redondo R, Dupre ME. Studying disability trends in aging populations. J Cross Cult Gerontol. 2015;30(1):21-49. http://dx.doi.org/10.1007/s10823-014-9245-6. PMid:25391217.

19. Lamb VL. Gender differences in correlates of disablement among the elderly in Egypt. Soc Sci Med. 1997;45(1):127-36. http://dx.doi.org/10.1016/S0277-9536(96)00326-7. PMid:9203277.

20. Crimmins EM, Saito Y. Change in the prevalence of diseases among older Americans: 1984-1994. Demogr Res. 2000;3(9):1-20. http://dx.doi.org/10.4054/DemRes.2000.3.9. 
21. Hirsch C, Anderson ML, Newman A, Kop W, Jackson S, Gottdiener J, et al. The association of race with frailty: The Cardiovascular Health Study. Ann Epidemiol. 2006;16(7):545-53. http://dx.doi.org/10.1016/j. annepidem.2005.10.003. PMid:16388967.

22. Gregg EW, Mangione CM, Cauley JA, Thompson TJ, Schwartz AV, Ensrud KE, et al. Diabetes and incidence of functional disability in older women. Diabetes Care. 2002;25(1):61-7. http://dx.doi.org/10.2337/ diacare.25.1.61. PMid:11772902.

23. Lee JS, Auyeung T-W, Leung J, KwokT, Leung PC, Woo J. Physical frailty in older adults is associated with metabolic and atherosclerotic risk factors and cognitive impairment independent of muscle mass. J Nutr Health Aging. 2011;15(10):857-62. http://dx.doi.org/10.1007/s12603-011-0134-1. PMid:22159773.

24. Jenkins KR. Obesity's effects on the onset of functional impairment among older adults. Gerontologist. 2004;44(2):206-16. http://dx.doi.org/10.1093/geront/44.2.206. PMid:15075417.

25. Blaum CS, Xue QL, Michelon E, Semba RD, Fried LP. The association between obesity and the frailty syndrome in older women: the Women's Health and Aging Studies. J Am Geriatr Soc. 2005;53(6):927-34 http://dx.doi.org/10.1111/j.1532-5415.2005.53300.x. PMid:15935013.

26. Espinoza SE, Fried LP. Risk factors for frailty in the older adult. Clin Geriatr. 2007;15:37-44.

27. Jarosz PA, Bellar A. Sarcopenic obesity: an emerging cause of frailty in older adults. Geriatr Nurs. 2009;30(1):64-70. http://dx.doi.org/10.1016/j.gerinurse.2008.02.010. PMid:19226689.

28. Inouye SK, Studenski S, Tinetti ME, Kuchel GA. Geriatric syndromes: clinical, research, and policy implications of a core geriatric concept. J Am Geriatr Soc. 2007;55(5):780-91. http://dx.doi.org/10.1111/ j.1532-5415.2007.01156.x. PMid:17493201.

29. Rockwood K, Howlett SE, MacKnight C, Beattie BL, Bergman H, Hébert R, et al. Prevalence, attributes, and outcomes of fitness and frailty in community-dwelling older adults: report from the Canadian study of health and aging. J Gerontol A Biol Sci Med Sci. 2004;59(12):1310-7. http://dx.doi.org/10.1093/ gerona/59.12.1310. PMid:15699531.

30. Lang PO, Michel JP, Zekry D. Frailty syndrome: a transitional state in a dynamic process. Gerontology. 2009;55(5):539-49. http://dx.doi.org/10.1159/000211949. PMid:19346741. 